\title{
Heat shock protein 27 is a potential indicator for response to YangZheng XiaoJi and chemotherapy agents in cancer cells
}

\author{
SIONED OWEN ${ }^{1,2^{*}}$, HUISHAN ZHAO ${ }^{1-3^{*}}$, ALWYN DART $^{1,2}$, YAMEI WANG $^{1-3}$, \\ FIONA RUGE ${ }^{1,2}$, YONG GAO ${ }^{4}, \mathrm{CONG} \mathrm{WEI}^{4,5}$, YILING WU ${ }^{4-6}$ and WEN G. JIANG ${ }^{1,2}$ \\ ${ }^{1}$ Cardiff China Medical Research Collaborative, Cardiff University School of Medicine; ${ }^{2}$ Cardiff University-Capital Medical \\ University Joint Centre for Biomedical Research, Cardiff University, Cardiff, UK; ${ }^{3}$ Cancer Institute and Key Laboratory \\ of Invasion and Metastasis (Beijing), Capital Medical University, Xitoutiao, Fengtai, Beijing; ${ }^{4}$ Yiling Medical \\ Research Institute, Shijiazhuang; ${ }^{5}$ State Key Laboratory of Collateral Disease Research and Innovation Medicine, \\ Shijiazhuang; ${ }^{6}$ Key Disciplines of State Administration of TCM for Collateral Disease, Shijiazhuang, Hebei, P.R. China
}

Received March 7, 2016; Accepted April 22, 2016

DOI: $10.3892 /$ ijo.2016.3685

\begin{abstract}
Heat shock protein 27 (HSP27) is a member of the heat shock protein family which has been linked to tumour progression and, most interestingly, to chemotherapy resistance in cancer patients. The present study examined the potential interplay between HSP27 and YangZheng XiaoJi, a traditional Chinese medicine used in cancer treatment. A range of cell lines from different tumour types including pancreatic, lung, gastric, colorectal, breast, prostate and ovarian cancer (both wild-type and resistant) were used. Levels and activation of HSP27 and its potential associated signalling pathways were evaluated by protein array and western blotting. Knockdown of HSP27 in cancer cells was achieved using siRNA. Localisation and co-localisation of HSP27 and other proteins were carried out by immunofluorescence. Cell growth and migration were evaluated in their response to a range of chemotherapeutic agents. The present study first identified, by way of protein array, that YangZheng XiaoJi was able to inhibit the phosphorylation of HSP27 protein in cancer cells. We further demonstrated that HSP27, which is co-localised with caspase-9, can be blocked from localising in focal adhesions and co-localising with caspase-9 by YangZheng XiaoJi. The study also demonstrated that YangZheng XiaoJi was able to sensitise cancer cells including those cells that were resistant to chemotherapy, to chemotherapeutic agents. Finally, knocking down HSP27 markedly reduced the migration of cancer cells
\end{abstract}

Correspondence to: Professor Wen G. Jiang, Cardiff China Medical Research Collaborative, Cardiff University School of Medicine, Henry Wellcome Building, Cardiff CF14 4XN, UK

E-mail: jiangw@cf.ac.uk

*Contributed equally

Key words: HSP27, YangZheng XiaoJi, protein kinase array, caspases, Focal adhesion kinase, lung cancer, pancreatic cancer, ovarian cancer, cellular migration and increased the sensitivity of cancer cells to the inhibitory effect on cellular migration by YangZheng XiaoJi. YangZheng $X i a o J i$ can act as an agent in first sensitising cancer cells to chemotherapy and secondly to overcome, to some degree, chemoresistance when used in an appropriate fashion in patients who have active HSP27.

\section{Introduction}

The heat shock proteins (HSPs) are ubiquitously expressed in almost all cells and across species. The protein family was so named owing to their initial discovery, namely, identified from cells under heat shock and is now known to be involved in a number of other cellular stresses including heat, carcinogens, mechanical and chemical stress $(1,2)$. These proteins serve as molecular chaperones and act as a mechanism to assist protein folding, repair damaged proteins, or assist in degrading the unwanted proteins after stress and injury, thus by doing so the proteins protect the injured cells from potentially lethal damage $(3,4)$. The HSP proteins are thus important regulators in normal physiology, but are also involved in diseases including cardiovascular, wound healing and cancer.

Similarly discovered from cells under heat shock, HSP27 has been found to be widely involved in other types of cell stress, including oxidative response (5-8). The HSP27 is a protein of approximately $27 \mathrm{kDa}$ in size and belongs to the HSP family in which sizes vary between 8-150 kDa. The main cellular function of HSP27 is protecting cells from becoming apoptotic, or anti-apoptotic. Although this role is critically important in homeostasis, it has serious implications in clinical cancer. Firstly, HSP27 has been found to be overexpressed in a variety of human cancers and linked to a poor outcome for those cancer patients (9-13); secondly, high levels of HSP27 in cancer cells have been shown to promote cancer cell growth (14-16); and thirdly, HSP27 was found to be extremely elevated following chemotherapy, most probably as a protective mechanism to chemical stress (17-19). In the latter case, HSP27 and HSP70 were two of the gene products that were upregulated in a cisplatin resistant ovarian cancer cell line (19). Thus, this has caused an enormous challenge 
to cancer treatment and is frequently linked to chemotherapy resistance in cancer.

The key mode of activation of HSP27 is by phosphorylation. Phosphorylation of HSP27 allows itself to form oligomers which may facilitate the chaperone process under cellular stress $(20,21)$. Phospho-HSP27 interacts with other proapoptotic proteins such as DAXX and ASK1 and therefore by blocking pro-apoptotic protein interaction blocks the apoptotic pathway $(22,23)$. Other known pathways of HSP27 include interaction with AKT1 and the oestrogen receptor. By interacting with these signalling proteins, phospho-HSP27 blocks some of their actions in cancer cells. The most commonly reported sites of phosphorylation with HSP27 are S15, S78, S82 and S86. Consequently, phosphorylated HSP27 protein levels have been found to be frequently raised in clinical cancer tissues and chemoresistant cancer cells $(24,25)$.

Together, it is suggested that HSP27 is a valid target for cancer treatment. Methods to either reduce the protein levels of HSP27 or the phosphorylation of HSP27, would be desirable in devising cancer treatment (26). A new anti-HSP27 agent, known as OGX427 (Apatorsen) has entered into a late phase clinical trial in patients with various malignant conditions including pancreatic, lung, bladder or prostate cancer, alone or in combination with other chemotherapies (27-30). Early studies have shown a favourable outcome from the new treatment.

There have been clinical trials which have shown that YangZheng XiaoJi (YZXJ), a combination of traditional Chinese medicinal herbs benefit cancer patients; however, how this mechanism of action is achieved remains unknown (31-34). The present study reports an accidental and surprising discovery that a traditional Chinese herbal medicine, known as YangZheng XiaoJi (YZXJ) used in treating patients with cancer, can suppress the phosphorylation of HSP27 and cell functions related to this protein.

\section{Materials and methods}

Materials. Antibodies to human HSP27 (sc-13132), caspase-3 (sc-7148), caspase-8 (sc-70501), caspase-9 (sc-17784), phosphoFAK (sc-81493), and GAPDH (sc-32233) were purchased from Santa Cruz Biotechnologies Inc. (Santa Cruz, CA, USA). Therapeutic agents including cisplatin, topotecan, pacilitaxol and 5-FU were purchased from Sigma-Aldrich (Poole, Dorset, UK). Antibodies to FAK (ab131435) and phospho-HSP-27 (S86) (ab17938) were purchased from Abcam (Cambridge, UK). FITC/TRITC-conjugated Phalloidin and FITC- and TRITC conjugated secondary antibodies were from Sigma-Aldrich. Secondary antibodies (fluorescence- and HRT-conjugated) were also from Sigma-Aldrich. Anti-HSP27 siRNA, control siRNA and transfection reagents were also obtained from Santa Cruz Biotechnologies Inc.

Cells. Human gastric cancer (AGS and HGC27), pancreatic cancer (PANC1), ovarian cancer (SKOV3 and COV504), lung cancer (A549 and SKMES1), breast cancer (MDA MB-231), prostate cancer (PC-3) cells were purchased from LGC Standard/ATCC (Southampton, UK). Ovarian cancer cells A2780 and its cisplatin resistant strain A2780/CP70 were gifts from Imperial College London (Dr Euan Stronach).
YangZheng XiaoJi extracts. An extract from YZXJ, named DME25 was prepared using a DMSO based method that has been described in full $(35,36)$. The herbal medicinal formula, YangZheng XiaoJi was obtained from Yiling Pharmaceuticals (Shijiazhuang, HeBei, China). The formula contained the following 16 ingredients: Panax ginseng C.A. Mey, Astragalus memebranaceus (Fisch.) Bge.var. mongholicus (Bge.) Hsiao, Ligustrum lucidum Ait, Curcuma phaeocaulis Val, Ganodema lucidum, Gynostemma pentaphylla (Thunb) Mak, Atractylodes macrocephala Koidz, Scutellaria barbata D.Don, Oldenlandia diffusa (willd.) Roxb, Poria cocos, Duchesnea indica Focke, Solanum lyratum Thunb, Artemisia scoparia (Bge.) Ki, Cynanchum paniculatum Kitag, Eupolyphaga sinensis Walker, and Gallus domesticus Brisson. For experimental use, the extract was diluted in the respective cell culture media and the dilution range was between 1:100 to $1: 2,000$.

Immunofluorescent staining. Cells, plated with test agents in 8 -well chamber slides, were first fixed using $4 \%$ formalin, lightly permeabilised with $0.1 \%$ Triton X100 for 5 min and blocked with a Tris buffer $(25 \mathrm{mM}, \mathrm{pH} 8.4)$ that contained $7.5 \%$ pre-immuned goat serum for $1 \mathrm{~h}$. Primary antibodies (including anti-HSP27, anti-phospho-HSP27 (S86), anticaspases), diluted in the blocking buffer was added to the respective slides which were kept in the dark at full humidity on a slow moving platform for $1 \mathrm{~h}$, and then washed thoroughly. FITC-tagged secondary antibodies were then added. After $1 \mathrm{~h}$, the slides were washed thoroughly and mounted using FluorSave ${ }^{\mathrm{TM}}$ (Calbiochem, Nottingham, UK). TRITCconjugated phalloidin was diluted at final concentration of $10 \mu \mathrm{g} / \mathrm{ml}$ and added to the cells together with the secondary antibodies. The slides were examined on an Olympus microscope and photographed using a Hamamatsu digital camera. The staining intensity was determined using ImageJ software.

Knockdown of HSP27. Cells at approximate $70 \%$ confluence were rinsed with BSS buffer. Anti-HSP27 siRNA, diluted in RNA free water was first mixed with a transfection reagent and left at room temperature for $30 \mathrm{~min}$ before being added to the cells. After $7 \mathrm{~h}$ medium was replaced and cells were left to incubate for another $24 \mathrm{~h}$. Expression of HSP27 was tested using RT-PCR.

Cell growth assay. Cancer cells were first seeded in 96-well tissue culture plates and allowed to adhere. The test materials and their combinations were then added to the cells, which were subsequently incubated for a period of $72 \mathrm{~h}$. After removing the culture media, cells were fixed with $4 \%$ formalin and stained with $0.5 \%$ Crystal violet. After extensive washing, the staining was extracted with $10 \%$ acetic acid and plates were read on a multiple channel plate reader at $540 \mathrm{~nm}$ (Elx800; Bio-Tek, Swindon, UK). The test regimens included chemotherapeutic agent alone, DME25 alone, DME25 and chemotherapeutic agent combination and DME25 pre-treatment followed by chemotherapeutic agent.

Protein arrays for detecting phosphorylation changes. Cancer cells at $90 \%$ confluence in two T75 tissue culture flasks were washed with BSS buffer and then placed into a fresh batch 


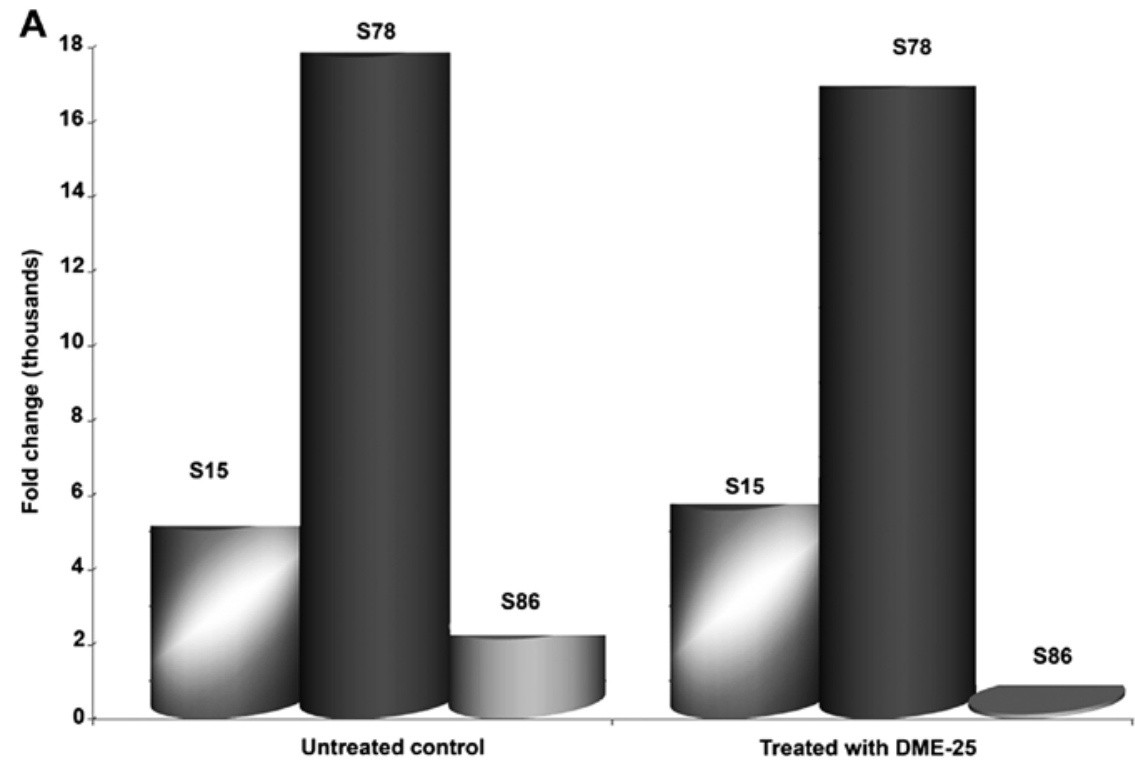

B

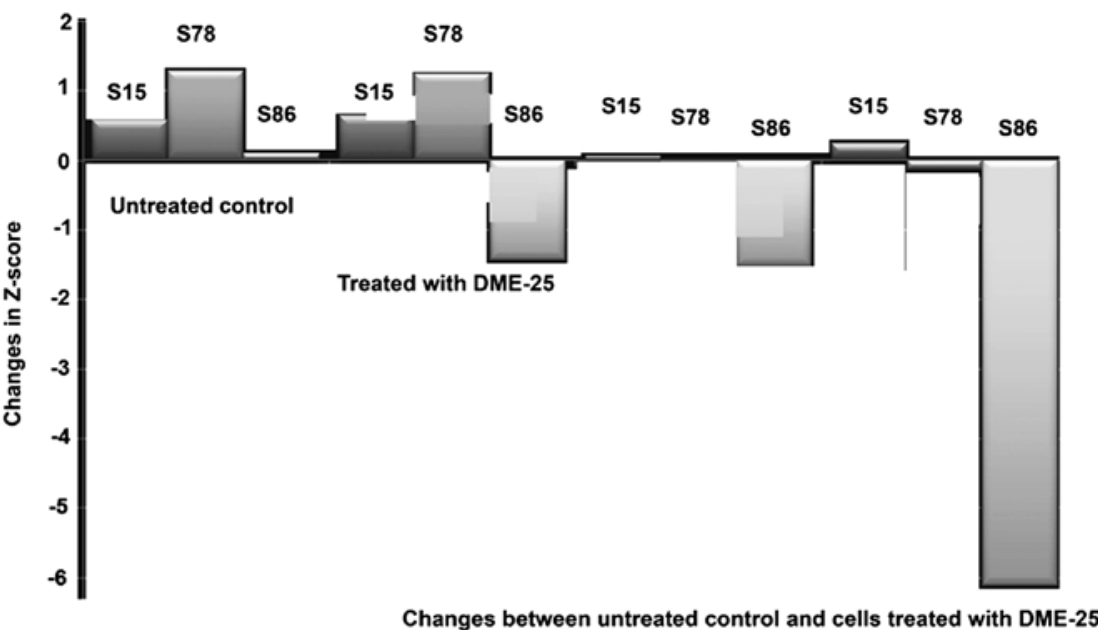

Figure 1. (A) Detection of HSP27 and phospho-HSP27 in SKMES1 lung cancer cells after treatment with DME-25 a YZXJ extract. (B) Changes in HSP27 and phospho-HSP27 in PANC-1 pancreatic cancer cells after treatment with DME-25 a YZXJ extract.

of DMEM supplemented with 5\% FCS. After $5 \mathrm{~h}$, treatment was added, again in 5\% FCS. After a 5-h period, cells were removed from the flasks with a cell scraper. The cells were pelleted using a centrifuge at 2,500 rpm for $5 \mathrm{~min}$. Lysis buffer was added to the cell pellets and placed on a spinning wheel for $1 \mathrm{~h}$ at $4^{\circ} \mathrm{C}$. The lysates were then spun at $12,000 \mathrm{x} \mathrm{g}$ for $10 \mathrm{~min}$ at $4^{\circ} \mathrm{C}$. The supernatants were carefully collected and the insolubles discarded. Based on absorbance the protein concentration in the cell lysates were quantified using the scatter line chart of Microsoft Excel and then adjusted to $2 \mathrm{mg} / \mathrm{ml}$. The samples were stored at $-20^{\circ} \mathrm{C}$ until use. Antibody based protein arrays, namely KAM850, which has 854 capture antibodies spotted on to each array slides (Kinexus Bioinformatics Ltd., Vancouver, Canada) were used in the present study. The following are the key parameters collected and used for the data analysis: Globally Normalized Signal Intensity, Background corrected intensity values are globally normalized. The Globally Normalized Signal Intensity was calculated by summing the intensities of all the net signal median values for a sample. Z Scores, Z score transformation corrects data internally within a single sample. Z Score Difference, The difference between the observed protein $\mathrm{Z}$ scores in samples in comparison. Z Ratios, Divide the Z Score Differences by the $\mathrm{SD}$ of all the differences for the comparison.

Electric cell-substrate impedance sensing (ECIS) based analyses on cell adhesion and cell migration. Briefly, 96-well W96E1 microarrays were used on the ECIS Ztheta instrument (Applied Biophysics Ltd., Troy, NJ, USA). Lung cancer cells were added to the wells of the array, followed by immediate tracking of cell adhesion over a range of frequencies $(1,000$ to $64,000 \mathrm{~Hz}$ ) using automated modules. The adhesion was analysed using the mathematical modelling methods as previously described. For cellular migration, confluent lung cancer monolayers in the arrays were electrically wounded $(2,000 \mathrm{~mA}$ for $20 \mathrm{sec}$ each), after which the migration of the cells was immediately tracked, again over a range of frequencies. All the experiments were conducted in triplicate.

Western blotting analysis of HSP27 proteins. Proteins, prepared in a similar fashion to that for protein analysis, were separated on a SDS-PAGE genes, following transfer of 
A
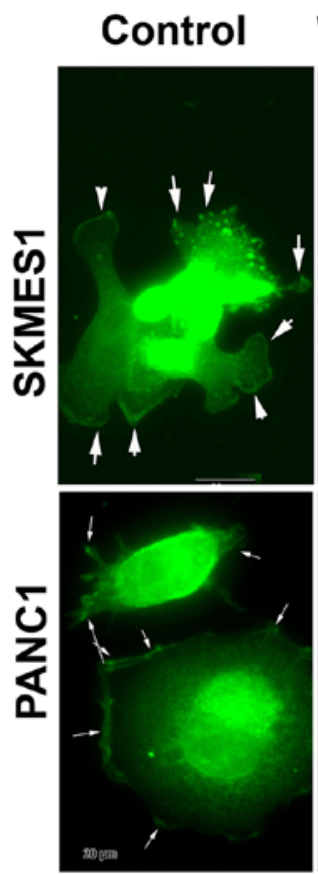
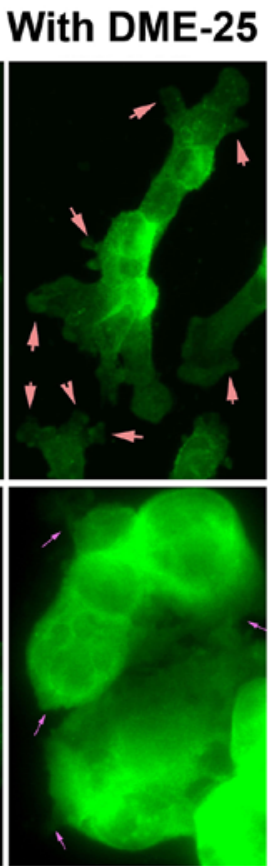

B

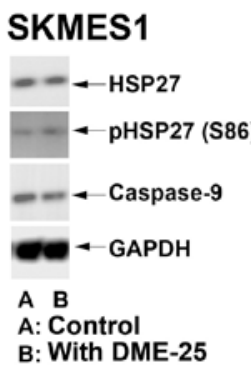

C

\section{PANC1}

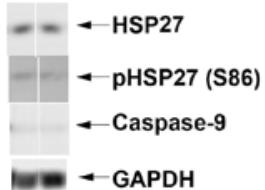

A B

A: Control

B:With DME-25
Total HSP 27
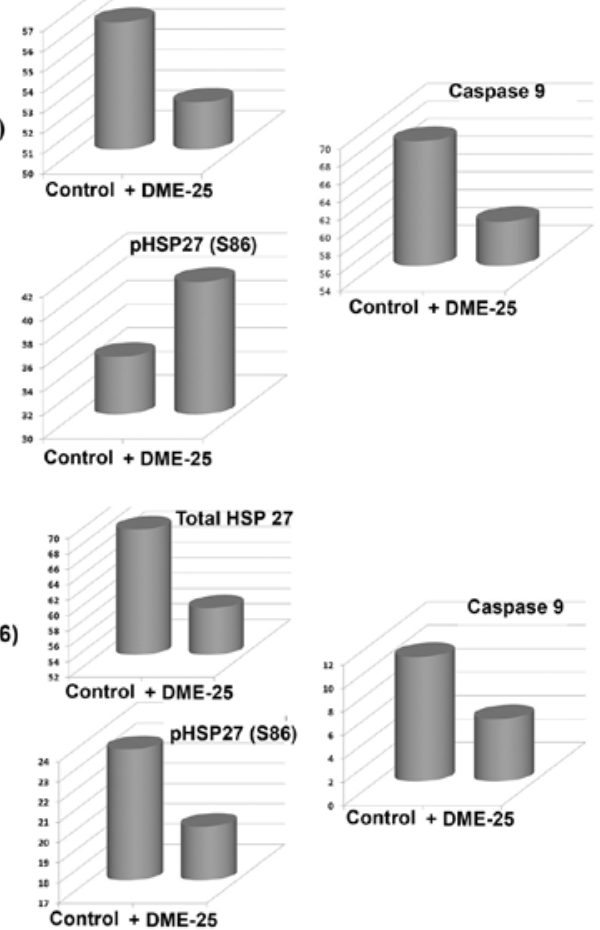

Figure 2. (A) Staining of phosphorylated HSP27 (S86) in SKMES1 human lung cancer cells (top panel) and pancreatic cancer PANC1 (bottom) after treatment with DME-25. In the control, phospho-HSP27 was seen predominantly in the focal adhesion complex regions (white arrows). Treatment with YZXJ extract DME25 resulted in almost complete loss of phospho-HSP27 from the focal adhesion complex (pink arrows). (B) Effects of DME-25 on HSP27 and its activation in SKMES1 cells as shown by western blotting. (C) Effects of DME-25 on HSP27 and its activation in PANC1 cells as shown by western blotting.

Table I. Effects of cisplatin on the growth of cancer cells in combination with DME25.

\begin{tabular}{|c|c|c|c|c|c|c|}
\hline \multirow[b]{2}{*}{ Cisplatin } & \multicolumn{2}{|c|}{$16 \mathrm{ng} / \mathrm{ml}$} & \multicolumn{2}{|c|}{$400 \mathrm{ng} / \mathrm{ml}$} & \multicolumn{2}{|c|}{$10 \mu \mathrm{g} / \mathrm{ml}$} \\
\hline & Control & YZXJ & Control & YZXJ & Control & YZXJ \\
\hline AGS & $7.9 \pm 2.5$ & $9.1 \pm 0.7$ & $20.8 \pm 2.0$ & $14.5 \pm 2.6$ & $93.1 \pm 0.5$ & $91.5 \pm 0.5$ \\
\hline MIAPACA2 & $50.1 \pm 4.5$ & $92.1 \pm 1.5$ & $77.5 \pm 1.5$ & $93.1 \pm 4.4$ & $77.8 \pm 2.5$ & $93.2 \pm 2.6$ \\
\hline A549 & $20.1 \pm 1.7$ & $12.2 \pm 2.7$ & $50.4 \pm 1.3$ & $44.1 \pm 1.7$ & $90.4 \pm 0.4$ & $89.9 \pm 0.2$ \\
\hline SKMES1 & $1.7 \pm 0.3$ & $34.6 \pm 1.7$ & $23.0 \pm 1.4$ & $46.3 \pm 2.0$ & $80.5 \pm 3.5$ & $86.9 \pm 2.6$ \\
\hline COV504 & $\mathrm{NC}$ & $3.8 \pm 6.2$ & $27.2 \pm 4.7$ & $43.4 \pm 2.7$ & $74.6 \pm 2.8$ & $85.1 \pm 1.3$ \\
\hline SKOV3 & $\mathrm{NC}$ & $17.2 \pm 1.9$ & $0.5 \pm 1.5$ & $9.8 \pm 2.6$ & $46.7 \pm 1.5$ & $66.7 \pm 2.7$ \\
\hline
\end{tabular}

NC, negative control.

proteins to nitrocellulose membranes, the membranes were probed with the respective antibodies in a set protocol that including extensive washings in between the antibody probing and finally detecting the antibody signals using chemilluminescence reagents. The membranes were visualised using an imager (G-Box; Syngene, Cambridge, UK).

\section{Results}

DME25 has a marked effect on the phosphorylation of HSP27. Using a protein array, we found that the YZXJ extract DME25 resulted in a marked reduction of phosphorylation of HSP27, particularly on Serine86 (S86) phosphorylation, in SKMES-1 lung cancer and PANC-1 pancreatic cancer cells (Fig. 1A and $\mathrm{B}$, respectively).

Localisation of HSP27 and phospho-HSP27 (S86) in cancer cells, assessed by immunofluorescence. HSP27 was seen broadly in the nucleus and in cytoplasmic region of lung cancer cells (Fig. 2A, top panel). It is very interesting to note that both total HSP27 and phospho-HSP27 was localised in focal adhesion and pseudopodia regions of the cells. Treatment of the lung cancer cells, SKMES1 with DME25 resulted in loss of phospho-HSP27 from the focal adhesion and pseudopodia 
A
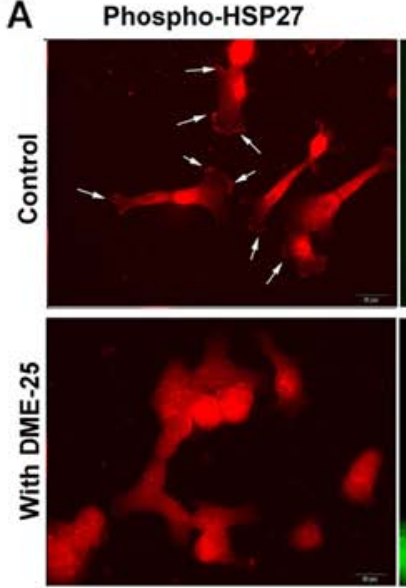

Caspase-9
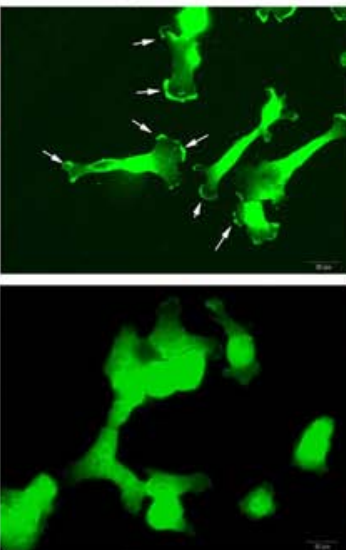

Composite
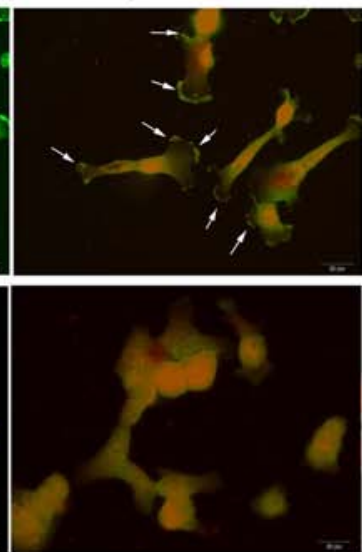

B Phospho-HSP27 Caspase-9 Composite

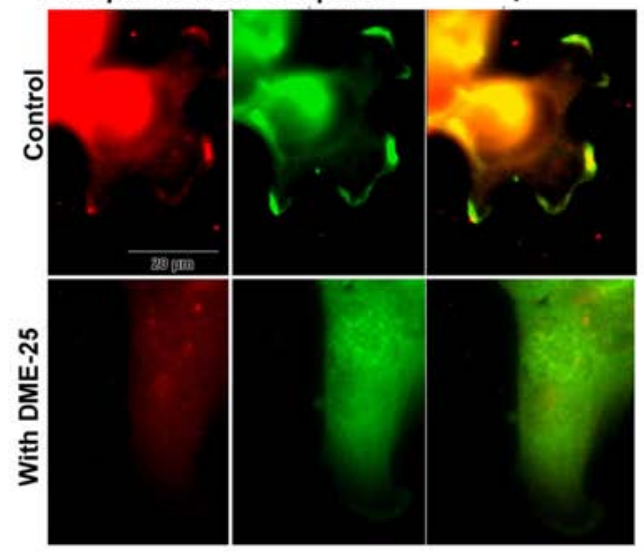

Figure 3. (A) Co-staining phospho-HSP27 and caspase-9 in human lung cancer SKMES-1 cells. Control cells displayed high levels of staining of both phosphoHSP27 and caspase-9, both also showing a high degree of co-localisation (white arrows). However, the co-localisation was eliminated by DME25 (bottom images). (B) Images under a higher power showing focal adhesion (FAC) and pseudopodia within the SKMES-1 cells.

A

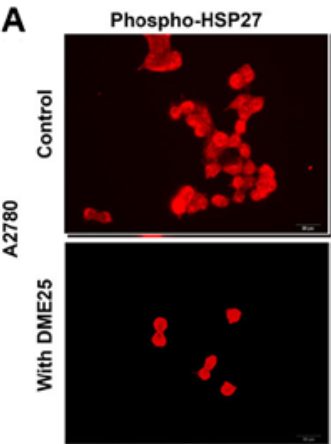

Phospho-HSP27

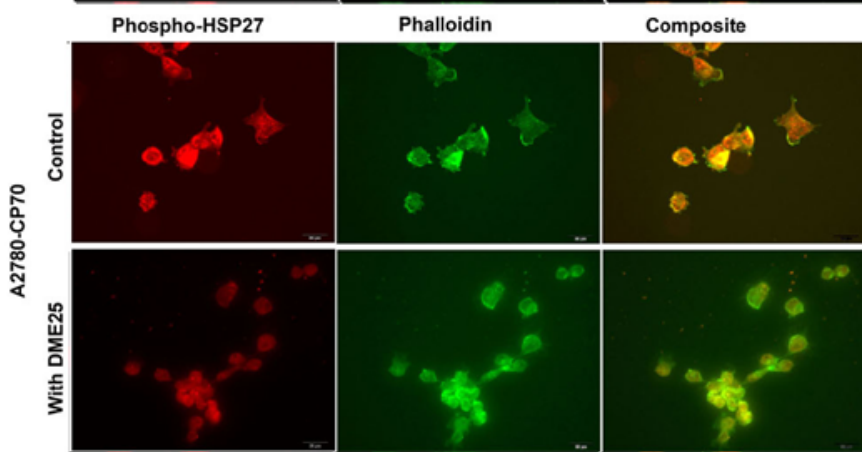

Phalloidin

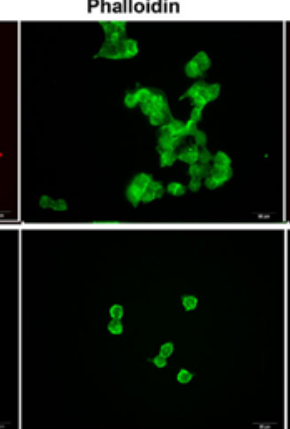

Phalloidin
Composite
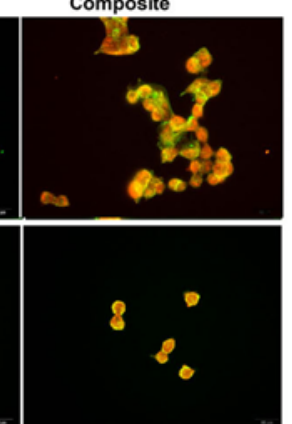

Composite
B

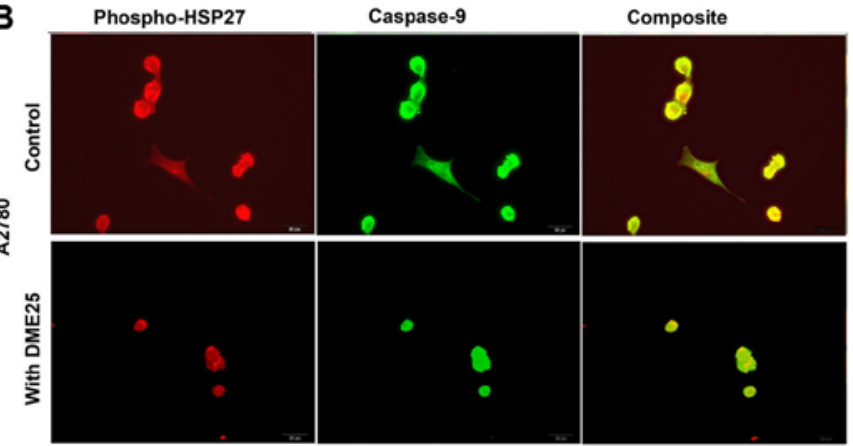

Phospho-HSP27

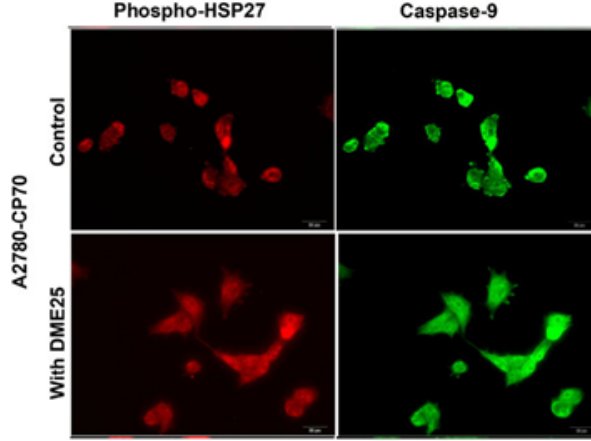

Composite

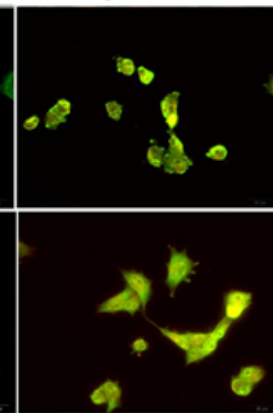

Figure 4. (A) Co-staining phospho-HSP27 and phalloidin in human wild-type ovarian cancer A2780 (top panel) and A2780-CP70 (bottom panel) cells. (B) The co-localisation between phospho-HSP27 and caspase-9 was shown in the respective two cell lines A2780 (top panel) and A2780-CP70 (bottom panel). DME25 is the extract from YZXJ.

regions of the cells, although the changes of total HSP27 did not appear to differ (Fig. 2). The same changes of phosphoHSP27 were seen in pancreatic cancer cells, PANC1 (Fig. 2A, bottom panel) as well as in ovarian cancer cell SKOV3 and gastric cancer AGS cells (data not shown). The inhibition on levels and activation of HSP27 was also demonstrated by western blotting analysis in both the lung and pancreatic cells (Fig. 2B and C, respectively).

Activated HSP27 is co-localised with caspase-9 in cancer cells, which is prevented when cells are treated with DME25. When co-stained for phospho-HSP27 (S86) and caspase-9, it was found that both molecules co-localised in regions of focal adhesion (FAC) and pseudopodia (Fig. 3A and B). It was very interesting to note that when cells were treated with DME25, this pattern of co-localisation appears to break (Fig. 3B).

Phospho-HSP27 and its co-localisation with filamentous actin and caspase-9 in cancer cells and in chemoresistant cancer cells. Using dual fluorescence staining, we have shown that phospho-HSP27 and F-actin did co-localise in FAC regions in both wild-type ovarian cancer A2780 (Fig. 4A, top panels) and in cisplatin resistant A2780/CP70 cells (Fig. 4 bottom panels). The same was seen with lung cancer cells (Fig. 5). In all the cells tested, treatment with DME25 reduced the location of phospho-HSP27 to the FAC region. The co-localisation 


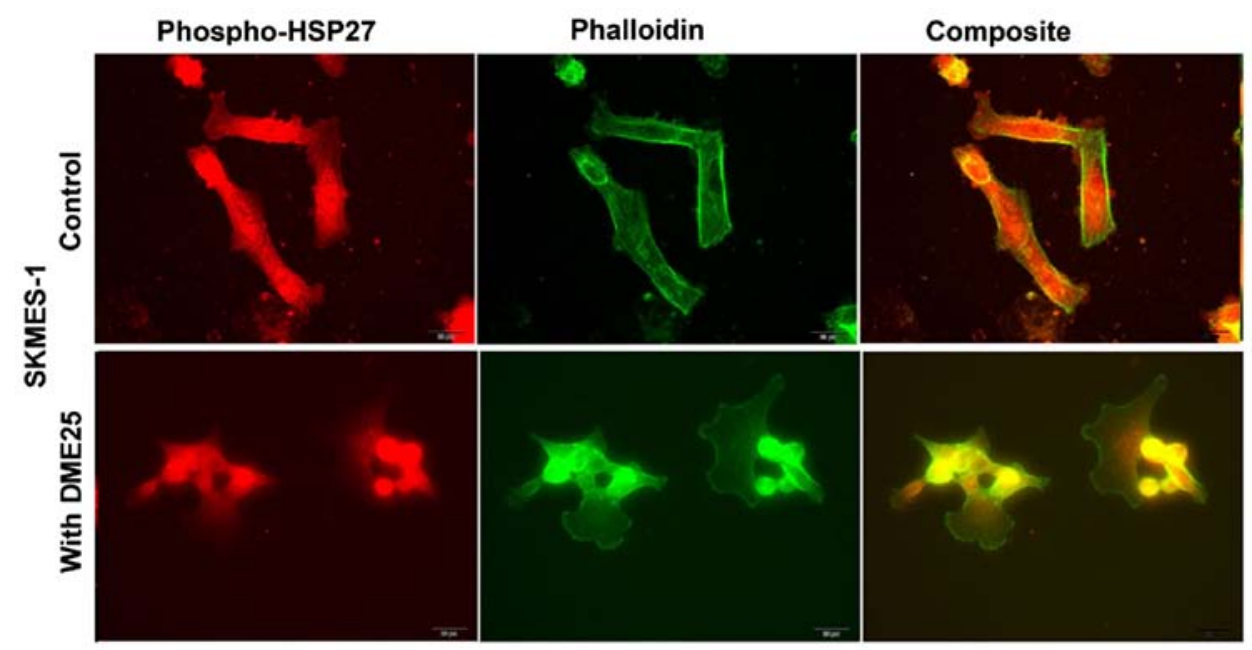

Figure 5. Co-staining phospho-HSP27 and Phalloidin in human lung cancer SKMES-1 cells.

Table II. Effects of pacilitaxel on the growth of cancer cells in combination with DME25.

\begin{tabular}{|c|c|c|c|c|c|c|}
\hline \multirow[b]{2}{*}{ Pacilitaxel } & \multicolumn{2}{|c|}{$3.2 \mathrm{ng} / \mathrm{ml}$} & \multicolumn{2}{|c|}{$80 \mathrm{ng} / \mathrm{ml}$} & \multicolumn{2}{|c|}{$2 \mu \mathrm{g} / \mathrm{ml}$} \\
\hline & Control & YZXJ & Control & YZXJ & Control & YZXJ \\
\hline AGS & $42.3 \pm 0.3$ & $45.2 \pm 2.2$ & $61.9 \pm 0.9$ & $63.4 \pm 2.6$ & $64.6 \pm 1.0$ & $64.9 \pm 0.2$ \\
\hline MIAPACA2 & $47.0 \pm 2.5$ & $89.3 \pm 2.8$ & $75.6 \pm 2.6$ & $91.6 \pm 2.1$ & $73.6 \pm 2.0$ & $91.0 \pm 5.1$ \\
\hline A549 & $46.3 \pm 0.7$ & $51.7 \pm 0.8$ & $66.2 \pm 1.0$ & $66.2 \pm 1.3$ & $69.7 \pm 1.7$ & $69.2 \pm 1.7$ \\
\hline SKMES1 & $20.0 \pm 2.4$ & $62.4 \pm 7.3$ & $55.7 \pm 2.3$ & $78.3 \pm 3.0$ & $63.2 \pm 1.9$ & $74.8 \pm 3.6$ \\
\hline COV504 & $38.7 \pm 2.7$ & $64.4 \pm 0.9$ & $57.2 \pm 0.6$ & $74.1 \pm 1.7$ & $55.6 \pm 0.9$ & $74.2 \pm 1.0$ \\
\hline SKOV3 & $34.2 \pm 1.6$ & $59.5 \pm 2.7$ & $40.0 \pm 1.1$ & $66.6 \pm 2.4$ & $49.6 \pm 1.6$ & $66.0 \pm 3.5$ \\
\hline
\end{tabular}

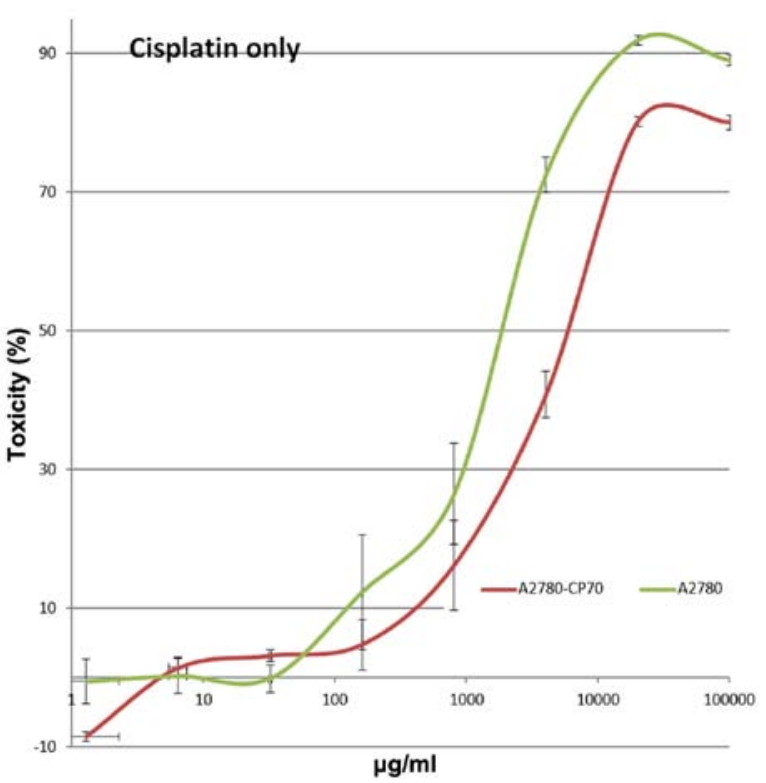

Figure 6. Wild-type A2780 and cisplatin resistance A2780/CP70 responded differently to cisplatin.

of phospho-HSP27 and caspase-9 in wild-type A2780 and cisplatin resistant $\mathrm{A} 2780 / \mathrm{CP} 70$ were also reduced in the presence of DME25 (Fig. 4B).
Effect of DME25 on the growth of ovarian cancer cells. A2780/ CP70 showed approximately 8 times less sensitivity to cisplatin compared with the wild-type parental cells (Fig. 6). Co-culture of both cisplatin and DME25 resulted in the cells becoming more sensitive to cisplatin, as seen for lung, gastric, pancreatic and ovarian cancer cells (Tables I-V). However, knocking down HSP27 by siRNA did not significantly influence the sensitivity of the cells to the chemotherapeutic agents (data not shown).

HSP27 shows marked influence on cell migration and acts synergistically with YangZheng XiaoJi on cancer cell migration. In light of the co-localisation of HSP27 and phalloidin at the focal adhesion regions of cancer cells and our previous reports on the impact of DME25 on the migration of various cells including cancer cells, we tested how HSP27 might affect cell migration. It was readily demonstrable that knocking down HSP27 resulted in a sustained reduction of cell migration (Fig. 7A and B). It was further confirmed that knocking down HSP27 increased sensitivity of cancer cells to low dosage chemotherapeutic agents and in particular when DME25 was present (Fig. 7C and D).

\section{Discussion}

The current study stemmed from a surprising finding in our search for the potential pathways that are influenced by 

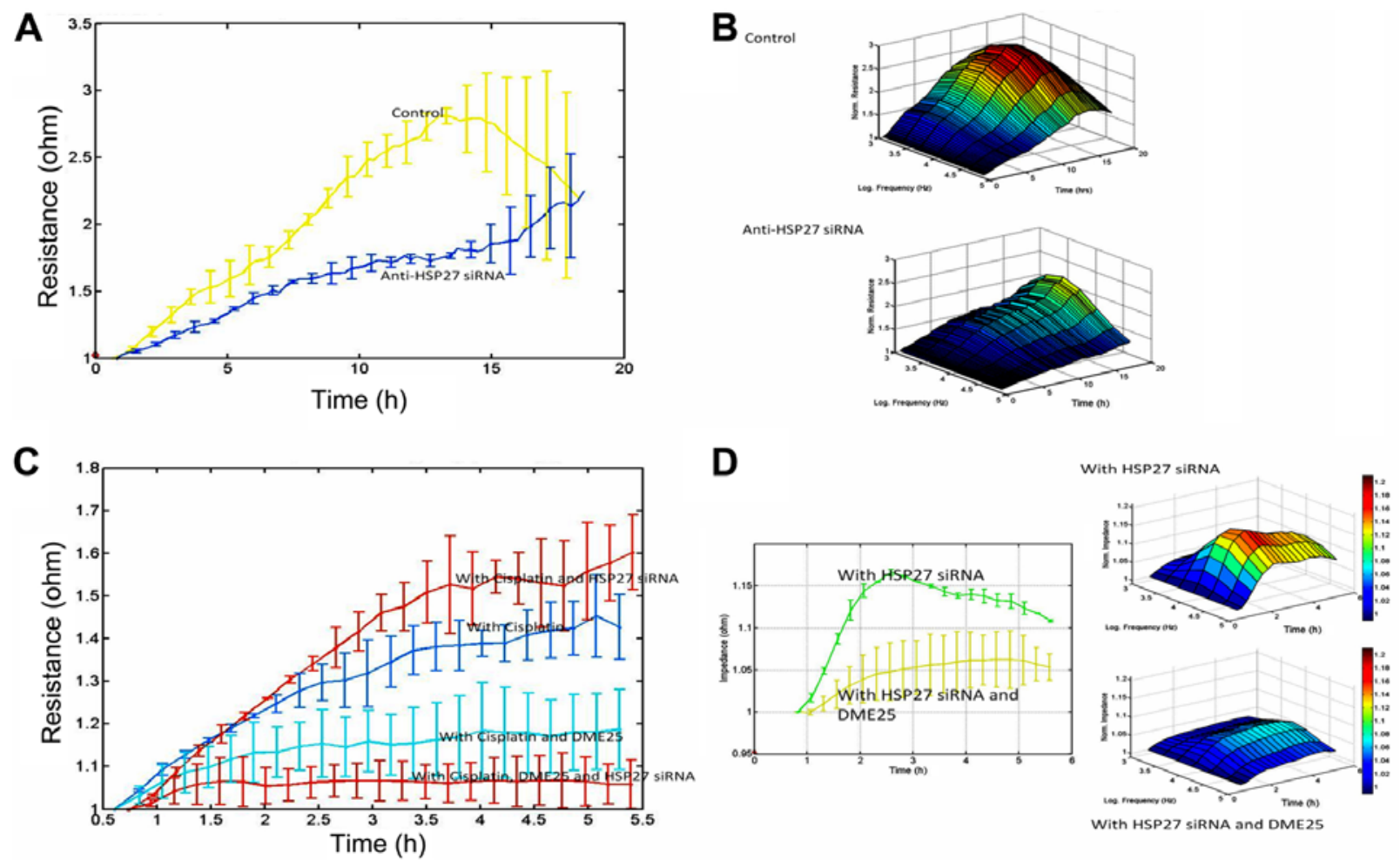

Figure 7. (A and B) Effects of knocking down HSP27 on the migration of SKMES1 cells. (C) The knockdown also increased the sensitivity of cancer cells to low concentration of drugs, in particular when combined with DME25. (D) Effects of knocking down HSP27 on the migration of PANC-1 cells which is further decreased in the presence of DME25.

Table III. Effects of 5-FU on the growth of cancer cells in combination with DME25.

\begin{tabular}{|c|c|c|c|c|c|c|}
\hline \multirow[b]{2}{*}{ 5-FU } & \multicolumn{2}{|c|}{$1.6 \mu \mathrm{g} / \mathrm{ml}$} & \multicolumn{2}{|c|}{$40 \mu \mathrm{g} / \mathrm{ml}$} & \multicolumn{2}{|c|}{$1000 \mu \mathrm{g} / \mathrm{ml}$} \\
\hline & Control & YZXJ & Control & YZXJ & Control & YZXJ \\
\hline AGS & $13.1 \pm 1.6$ & $3.6 \pm 1.8$ & $59.6 \pm 0.8$ & $56.8 \pm 1.6$ & $79.2 \pm 0.6$ & $75.3 \pm 2.1$ \\
\hline MIAPACA2 & $\mathrm{NC}$ & $57.8 \pm 1.5$ & $33.4 \pm 5.9$ & $70.8 \pm 3.2$ & $64.4 \pm 3.5$ & $88.6 \pm 7.8$ \\
\hline A549 & $15.0 \pm 3.1$ & $12.7 \pm 4.1$ & $59.2 \pm 2.0$ & $57.6 \pm 3.5$ & $70.3 \pm 1.8$ & $69.9 \pm 2.1$ \\
\hline SKMES1 & $10.5 \pm 2.3$ & $29.0 \pm 1.4$ & $51.9 \pm 3.4$ & $65.0 \pm 1.3$ & $57.5 \pm 2.6$ & $68.2 \pm 2.1$ \\
\hline COV504 & $15.6 \pm 1.4$ & $48.2 \pm 1.6$ & $40.5 \pm 2.4$ & $59.1 \pm 2.6$ & $50.4 \pm 0.9$ & $63.7 \pm 1.6$ \\
\hline SKOV3 & $10.4 \pm 0.8$ & $20.9 \pm 2.8$ & $32.7 \pm 43.5 \pm 0.9$ & $43.9 \pm 1.9$ & $46.0 \pm 1.8$ & $60.9 \pm 1.4$ \\
\hline
\end{tabular}

NC, negative control.

DME25, a traditional Chinese medicinal formula used in cancer treatment.

HSP27, YangZheng XiaoJi and sensitivity to chemotherapeutic agents. The role of HSP27 in the sensitivity to chemotherapy agents is not without controversy. For example, it has been reported recently that overexpression of HSP 27 in pancreatic cancer cells would increase the sensitivity of the cancer cells to gemcitabine (37). Although reasons for this are not clear, the type of drugs used in the study may be an explanation, as these drugs are transported and act in cancer cells via different mechanisms.

HSP27 acts as a cyto-protective molecule during androgen independence in prostate cancer patients and in prostate cancer cell models (38). Likewise, levels of HSP27 correlated with resistance to irinotecan in colorectal cancer cells (39). HSP27, together with HSP70 is linked to the sensitivity of colorectal cancer to the naturally-occurring anticancer agent curcumin (40).

Knocking down HSP27 sensitises glioblastoma multiforme tumour cells to the HSP90 inhibitor, 17-N-allylamino-17demethoxygeldanamycin (17-AAG) and staurosporine by changes in apoptosis (41). The same was seen in glioma cells, in that silencing HSP27 resulted in an increase in apoptosis in response to temozolomide and quercetin (42).

HSP27, YangZheng XiaoJi and cell migration. The finding that HSP27 is co-localised with phalloidin to the focal adhesion 
Table IV. Effects of topotecan on the growth of cancer cells in combination with DME25.

\begin{tabular}{|c|c|c|c|c|c|c|}
\hline \multirow[b]{2}{*}{ Topotecan } & \multicolumn{2}{|c|}{$3.2 \mathrm{ng} / \mathrm{ml}$} & \multicolumn{2}{|c|}{$80 \mathrm{ng} / \mathrm{ml}$} & \multicolumn{2}{|c|}{$2 \mu \mathrm{g} / \mathrm{ml}$} \\
\hline & Control & YZXJ & Control & YZXJ & Control & YZXJ \\
\hline AGS & $7.6 \pm 8.6$ & $18.3 \pm 3.7$ & $46.0 \pm 5.8$ & $65.9 \pm 2.6$ & $88.1 \pm 2.0$ & $86.5 \pm 2.8$ \\
\hline MIAPACA2 & $0.9 \pm 0.9$ & $65.6 \pm 4.1$ & $39.5 \pm 3.3$ & $80.2 \pm 2.6$ & $66.1 \pm 0.9$ & $91.6 \pm 4.5$ \\
\hline A549 & $\mathrm{NC}$ & $\mathrm{NC}$ & $48.9 \pm 4.3$ & $60.0 \pm 2.0$ & $68.8 \pm 1.3$ & $66.3 \pm 1.6$ \\
\hline SKOV3 & $11 \pm 0.7$ & $30.2 \pm 2.1$ & $38.9 \pm 1.1$ & $50.1 \pm 2.7$ & $58.2 \pm 0.9$ & $62.1 \pm 2.8$ \\
\hline COV504 & $\mathrm{NC}$ & $23.1 \pm 0.8$ & $24.9 \pm 5.1$ & $50.12 \pm 12.5$ & $39.4 \pm 1.8$ & $79.9 \pm 2.8$ \\
\hline SKMES1 & $7.8 \pm 0.6$ & $40.4 \pm 2.8$ & $62.3 \pm 1.4$ & $88.4 \pm 3.4$ & $50.6 \pm 1.1$ & $72.6 \pm 2.7$ \\
\hline
\end{tabular}

Table V. Effects of cisplatin on the growth of wild-type and cisplatin-resistant ovarian cancer cells in combination with DME25.

\begin{tabular}{lllllll}
\hline & \multicolumn{2}{c}{$\mathrm{A} 2780$} & & \multicolumn{2}{c}{$\mathrm{A} 2780 / \mathrm{CP} 70$} \\
\cline { 2 - 3 } \cline { 5 - 6 } Treatment & $160 \mathrm{ng} / \mathrm{ml}$ & $4 \mu \mathrm{g} / \mathrm{ml}$ & & $160 \mathrm{ng} / \mathrm{ml}$ & $4 \mu \mathrm{g} / \mathrm{ml}$ \\
\hline Cisplatin only & $12.3 \pm 8.2$ & $72.5 \pm 2.5$ & & $4.7 \pm 4.0$ & $40.8 \pm 8.6$ \\
Cisplatin + YZXJ & $72.4 \pm 3.6$ & $80.5 \pm 3.3$ & & $26.8 \pm 0.4$ & $46.3 \pm 1.3$ \\
\hline
\end{tabular}

regions of cancer cells is interesting. From the immunofluorescence staining, HSP27 particularly the phosphorylated form of the protein, is frequently co-localised with Phallodin at the focal adhesion regions of cancer cells, where caspase- 9 is also seen. It is of interest to note that inclusion of $Y Z X J$ extract DME25 in the study markedly reduce the presence of phospho-HSP27 (S86) at the focal adhesions. Given the key role of focal adhesion in cell-matrix adhesion and cellular migration, it is plausible to suggest that activation of HSP27 (by way of phosphorylation) coordinates with other proteins in the focal adhesion area, such as integrins and the focal adhesion kinase (FAK) to regulate the adhesion and migration of cancer cells. We have recently reported that YZXJ was able to inhibit the phosphorylation of FAK in cancer cells and in endothelial cells $(35,43)$.

Together with the finding that knocking down HSP27 resulted in an increase in cellular migration in cancer cells, it is suggested that HSP27, in particular when combined with YZXJ, is an important regulator of EMT reversal or MET. It has been reported recently that HSP27 is key to IL-6 dependent and IL-6 independent EMT in prostate cancer cells, by acting on IL-6 induced activation of STAT3/Twist and Snail $(44,45)$. It is also involved in EGF induced EMT in prostate cancer cells by influencing the migration of these cells $(46,47)$. Other than the reported effects on cancer cells, HSP27 has also been shown to be a mediator for angiogenesis (48), suggesting that HSP27 is involved in a wider range of processes in cancer development and progression.

Taken together, it is clear that HSP27 is a viable target in cancer treatment and that a combined approach, with either $Y Z X J$ or another method, would be a valid consideration when devising a therapy in either targeting HSP27 or in certain chemoresistance cases.

\section{Acknowledgements}

The authors wish to thank Cancer Research Wales, National Research Network for Wales-Ser Cymru and the Albert Hung Foundation for supporting their work.

\section{References}

1. Bonnycastle LL, Yu CE, Hunt CR, Trask BJ, Clancy KP, Weber JL, Patterson D and Schellenberg GD: Cloning, sequencing, and mapping of the human chromosome 14 heat shock protein gene (HSPA2). Genomics 23: 85-93, 1994.

2. Dix DJ, Allen JW, Collins BW, Mori C, Nakamura N, Poorman-Allen P, Goulding EH and Eddy EM: Targeted gene disruption of Hsp70-2 results in failed meiosis, germ cell apoptosis, and male infertility. Proc Natl Acad Sci USA 93: 3264$3268,1996$.

3. Bowen-Jones D, Fantes $\mathbf{J}$ and Gupta R: Diabetes and heat shock protein. Nature 355: 119-120, 1992.

4. Keyse SM and Emslie EA: Oxidative stress and heat shock induce a human gene encoding a protein-tyrosine phosphatase. Nature 359: 644-647, 1992.

5. Ackerley S, James PA, Kalli A, French S, Davies KE and Talbot K: A mutation in the small heat-shock protein HSPB1 leading to distal hereditary motor neuronopathy disrupts neurofilament assembly and the axonal transport of specific cellular cargoes. Hum Mol Genet 15: 347-354, 2006.

6. Evgrafov OV, Mersiyanova I, Irobi J, Van Den Bosch L, Dierick I, Leung CL, Schagina O, Verpoorten N, Van Impe K, Fedotov V, et al: Mutant small heat-shock protein 27 causes axonal CharcotMarie-Tooth disease and distal hereditary motor neuropathy. Nat Genet 36: 602-606, 2004.

7. Hickey E, Brandon SE, Potter R, Stein G, Stein J and Weber LA: Sequence and organization of genes encoding the human $27 \mathrm{kDa}$ heat shock protein. Nucleic Acids Res 14: 4127-4145, 1986.

8. Wyttenbach A, Sauvageot O, Carmichael J, Diaz-Latoud C, Arrigo AP and Rubinsztein DC: Heat shock protein 27 prevents cellular polyglutamine toxicity and suppresses the increase of reactive oxygen species caused by huntingtin. Hum Mol Genet 11: 1137-1151, 2002.

9. Erkizan O, Kirkali G, Yörükoğlu K and Kirkali Z: Significance of heat shock protein-27 expression in patients with renal cell carcinoma. Urology 64: 474-478, 2004.

10. Langdon SP, Rabiasz GJ, Hirst GL, King RJ, Hawkins RA, Smyth JF and Miller WR: Expression of the heat shock protein HSP27 in human ovarian cancer. Clin Cancer Res 1: 1603-1609, 1995.

11. Whelan RD and Hill BT: Differential expression of steroid receptors, hsp27, and pS2 in a series of drug resistant human breast tumor cell lines derived following exposure to antitumor drugs or to fractionated X-irradiation. Breast Cancer Res Treat 26: 23-39, 1993.

12. Zimmermann M, Nickl S, Lambers C, Hacker S, Mitterbauer A, Hoetzenecker K, Rozsas A, Ostoros G, Laszlo V, Hofbauer H, et al: Discrimination of clinical stages in non-small cell lung cancer patients by serum HSP27 and HSP70: A multi-institutional case-control study. Clin Chim Acta 413: 1115-1120, 2012. 
13. Giaginis C, Daskalopoulou SS, Vgenopoulou S, Sfiniadakis I, Kouraklis G and Theocharis SE: Heat Shock Protein-27, -60 and -90 expression in gastric cancer: Association with clinicopathological variables and patient survival. BMC Gastroenterol 9: 14, 2009.

14. Garrido C, Brunet M, Didelot C, Zermati Y, Schmitt E and Kroemer G: Heat shock proteins 27 and 70: Anti-apoptotic proteins with tumorigenic properties. Cell Cycle 5: 2592-2601, 2006.

15. Gibert B, Eckel B, Gonin V, Goldschneider D, Fombonne J, Deux B, Mehlen P, Arrigo AP, Clézardin P and Diaz-Latoud C: Targeting heat shock protein 27 (HspB1) interferes with bone metastasis and tumour formation in vivo. Br J Cancer 107: 63-70, 2012.

16. Schweiger T, Nikolowsky C, Starlinger P, Traxler D, Zimmermann M, Birner P, Hegedüs B, Dome B, Bergmann M, Mildner M, et al: Stromal expression of heat-shock protein 27 is associated with worse clinical outcome in patients with colorectal cancer lung metastases. PLoS One 10: e0120724, 2015.

17. Andrieu C, Taieb D, Baylot V, Ettinger S, Soubeyran P, De-Thonel A, Nelson C, Garrido C, So A, Fazli L, et al: Heat shock protein 27 confers resistance to androgen ablation and chemotherapy in prostate cancer cells through eIF4E. Oncogene 29: 1883-1896, 2010.

18. Musiani D, Konda JD, Pavan S, Torchiaro E, Sassi F, Noghero A Erriquez J, Perera T, Olivero M and Di Renzo MF: Heat-shock protein 27 (HSP27, HSPB1) is up-regulated by MET kinase inhibitors and confers resistance to MET-targeted therapy. FASEB J 28: 4055-4067, 2014.

19. Yamamoto K, Okamoto A, Isonishi S, Ochiai K and Ohtake Y: Heat shock protein 27 was up-regulated in cisplatin resistant human ovarian tumor cell line and associated with the cisplatin resistance. Cancer Lett 168: 173-181, 2001.

20. Kuramitsu Y, Wang Y, Taba K, Suenaga S, Ryozawa S, Kaino S, Sakaida I and Nakamura K: Heat-shock protein 27 plays the key role in gemcitabine-resistance of pancreatic cancer cells Anticancer Res 32: 2295-2299, 2012.

21. Rogalla T, Ehrnsperger M, Preville X, Kotlyarov A, Lutsch G Ducasse C, Paul C, Wieske M, Arrigo AP, Buchner J, et al: Regulation of Hsp27 oligomerization, chaperone function, and protective activity against oxidative stress/tumor necrosis factor alpha by phosphorylation. J Biol Chem 274: 18947-18956, 1999.

22. Charette SJ and Landry J: The interaction of HSP27 with Daxx identifies a potential regulatory role of HSP27 in Fas-induced apoptosis. Ann N Y Acad Sci 926: 126-131, 2000.

23. Charette SJ, Lavoie JN, Lambert H and Landry J: Inhibition of Daxx-mediated apoptosis by heat shock protein 27. Mol Cell Biol 20: 7602-7612, 2000.

24. Kang D, Choi HJ, Kang S, Kim SY, Hwang YS, Je S, Han Z, Kim JH and Song JJ: Ratio of phosphorylated HSP27 to nonphosphorylated HSP27 biphasically acts as a determinant of cellular fate in gemcitabine-resistant pancreatic cancer cells. Cell Signal 27: 807-817, 2015.

25. Nakashima M, Adachi S, Yasuda I, Yamauchi T, Kawaguchi J, Itani M, Yoshioka T, Matsushima-Nishiwaki R, Hirose Y, Kozawa O, et al: Phosphorylation status of heat shock protein 27 plays a key role in gemcitabine-induced apoptosis of pancreatic cancer cells. Cancer Lett 313: 218-225, 2011

26. Ciocca DR and Calderwood SK: Heat shock proteins in cancer: Diagnostic, prognostic, predictive, and treatment implications. Cell Stress Chaperones 10: 86-103, 2005

27. Baylot V, Andrieu C, Katsogiannou M, Taieb D, Garcia S, Giusiano S, Acunzo J, Iovanna J, Gleave M, Garrido C, et al: OGX-427 inhibits tumor progression and enhances gemcitabine chemotherapy in pancreatic cancer. Cell Death Dis 2: e221, 2011

28. Kamada M, So A, Muramaki M, Rocchi P, Beraldi E and Gleave M: Hsp27 knockdown using nucleotide-based therapies inhibit tumor growth and enhance chemotherapy in human bladder cancer cells. Mol Cancer Ther 6: 299-308, 2007.

29. Lelj-Garolla B, Kumano M, Beraldi E, Nappi L, Rocchi P, Ionescu DN, Fazli L, Zoubeidi A and Gleave ME: Hsp27 Inhibition with OGX-427 sensitizes non-small cell lung cancer cells to erlotinib and chemotherapy. Mol Cancer Ther 14: 1107-1116, 2015.

30. Matsui Y, Hadaschik BA, Fazli L, Andersen RJ, Gleave ME and So AI: Intravesical combination treatment with antisense oligonucleotides targeting heat shock protein-27 and HTI-286 as a novel strategy for high-grade bladder cancer. Mol Cancer Ther 8: 2402-2411, 2009.
31. Li Sun JR: Yei Tan, Xuedong Gao: Yang capsule in treatment of hepatocellular carcinoma with interventional chemotherapy random double-blind, multicenter clinical study. World Chin J 8 : 688-691, 2013.

32. Ligan Xing XZ, Li G, Zhang X, Sun X, Guo Q and Yu J: Controlled clinical studies in the effects of Yang capsule in advanced lung cancer in combination with chemotherapy. China J Cancer Prev Treat 21: 384-386, 2014.

33. Xingjun Cui WM and Bi X: Effect of Yangzheng Xiaoji capsule on cellular immune function in patients with advanced gastric cancer chemotherapy. Chin J Difficult Complicated Cases 10: 703-704, 2011.

34. Xue Kan SF and Ji J: Meta-anlaysis of the safety of Yangzheng Xiaoji capsule for the treatment of cancer and precancerosis. Chin J Clin Oncol 40: 1318-1323, 2013.

35. Jiang WG, Ye L, Ji K, Frewer N, Ji J and Mason MD: Inhibitory effects of Yangzheng Xiaoji on angiogenesis and the role of the focal adhesion kinase pathway. Int J Oncol 41: 1635-1642, 2012.

36. Ye L, Ji K, Frewer N, Ji J and Jiang WG: Impact of Yangzheng Xiaoji on the adhesion and migration of human cancer cells: The role of the AKT signalling pathway. Anticancer Res 32: 2537-2543, 2012

37. Guo Y, Ziesch A, Hocke S, Kampmann E, Ochs S, De Toni EN Göke B and Gallmeier E: Overexpression of heat shock protein 27 (HSP27) increases gemcitabine sensitivity in pancreatic cancer cells through S-phase arrest and apoptosis. J Cell Mol Med 19: 340-350, 2015

38. Rocchi P, So A, Kojima S, Signaevsky M, Beraldi E, Fazli L, Hurtado-Coll A, Yamanaka K and Gleave M: Heat shock protein 27 increases after androgen ablation and plays a cytoprotective role in hormone-refractory prostate cancer. Cancer Res 64: 6595-6602, 2004.

39. Choi DH, Ha JS, Lee WH, Song JK, Kim GY, Park JH, Cha HJ, Lee BJ and Park JW: Heat shock protein 27 is associated with irinotecan resistance in human colorectal cancer cells. FEBS Lett 581: 1649-1656, 2007.

40. Rashmi R, Santhosh Kumar TR and Karunagaran D: Human colon cancer cells differ in their sensitivity to curcumin-induced apoptosis and heat shock protects them by inhibiting the release of apoptosis-inducing factor and caspases. FEBS Lett 538: 19-24, 2003.

41. Belkacemi L and Hebb MO: HSP27 knockdown produces synergistic induction of apoptosis by HSP90 and kinase inhibitors in glioblastoma multiforme. Anticancer Res 34: 4915-4927, 2014.

42. Jakubowicz-Gil J, Langner E, Badziul D, Wertel I and Rzeski W: Silencing of Hsp27 and Hsp72 in glioma cells as a tool for programmed cell death induction upon temozolomide and quercetin treatment. Toxicol Appl Pharmacol 273: 580-589, 2013.

43. Jiang WG, Ye L, Ruge F, Owen S, Martin T, Sun PH, Sanders AJ, Lane J, Satherley L, Weeks HP, et al: Yangzheng Xiaoji exerts anti-tumour growth effects by antagonising the effects of HGF and its receptor, cMET, in human lung cancer cells. J Transl Med 13: 280, 2015

44. Shiota M, Bishop JL, Nip KM, Zardan A, Takeuchi A, Cordonnier T, Beraldi E, Bazov J, Fazli L, Chi K, et al: Hsp27 regulates epithelial mesenchymal transition, metastasis, and circulating tumor cells in prostate cancer. Cancer Res 73: 3109-3119, 2013

45. Wettstein G, Bellaye PS, Kolb M, Hammann A, Crestani B, Soler P, Marchal-Somme J, Hazoume A, Gauldie J, Gunther A, et al: Inhibition of HSP27 blocks fibrosis development and EMT features by promoting Snail degradation. FASEB J 27: 1549-1560, 2013.

46. Cordonnier T, Bishop JL, Shiota M, Nip KM, Thaper D, Vahid S, Heroux D, Gleave $M$ and Zoubeidi A: Hsp27 regulates $\mathrm{EGF} / \beta$-catenin mediated epithelial to mesenchymal transition in prostate cancer. Int J Cancer 136: E496-E507, 2015.

47. Voll EA, Ogden IM, Pavese JM, Huang X, Xu L, Jovanovic BD and Bergan RC: Heat shock protein 27 regulates human prostate cancer cell motility and metastatic progression. Oncotarget 5 : 2648-2663, 2014

48. Thuringer D, Jego G, Wettstein G, Terrier O, Cronier L, Yousfi N, Hébrard S, Bouchot A, Hazoumé A, Joly AL, et al: Extracellular HSP27 mediates angiogenesis through Toll-like receptor 3. FASEB J 27: 4169-4183, 2013. 